2015-08

\title{
Reflections on the authorship of space
}

\section{technology}

Griffin, Joanna

http://hdl.handle.net/10026.1/10680

10.1016/j.spacepol.2015.06.001

Space Policy

Elsevier BV

All content in PEARL is protected by copyright law. Author manuscripts are made available in accordance with publisher policies. Please cite only the published version using the details provided on the item record or document. In the absence of an open licence (e.g. Creative Commons), permissions for further reuse of content should be sought from the publisher or author. 
Viewpoint

\title{
Reflections on the authorship of space technology
}

\author{
Joanna Griffin \\ Transtechnology Research, Portland Square, Plymouth University, Drake Circus, Plymouth PL4 8AA, UK
}

\section{A $\quad$ R $T$ T I C C L E I I N F O}

\section{Article history:}

Received 29 May 2015

Accepted 1 June 2015

Available online 19 June 2015

\section{Keywords:}

Moon

Ownership

Artists

Authorship

Chandrayaan-1

India

Drawing

Imaginaries

Participation

\begin{abstract}
A B S T R A C T
The paper offers a proposition in which the notion of the 'ownership' of outer space is substituted for that of 'authorship'. The notion of authorship draws attention to the processes of critical thinking, recontextualization and resistances to space technology that take place in social domains where no clear role exists either as audience or user of space technology. The proposition responds in part to interventions made by artists in recent years into the workplaces of space technologists and, incrementally, into the imaginaries that inform the kinds of activities that happen in space. Artistic processes expose the reception of space technology at an intimate scale where the agencies of the viewer to observe, absorb and rethink converge with the shaping of space technology via state mediation and space agency imperatives. The constituency of collective authorship to which space technologies are subject is revealed in unexpected ways through artistic intervention that suggests a reappraisal of some of the terms of reference guiding space policy.
\end{abstract}

() 2015 Elsevier Ltd. All rights reserved.

\section{Introduction}

The proposition of this paper emerges from my own interactions with the astronautical community as an artist-in-residence, teacher and researcher in space science labs, conferences and through a series of co-produced public engagements. ${ }^{1}$ It relates more specifically to a project called Moon Vehicle which was an artist-led initiative that responded to the mission of India's Chandrayaan-1 spacecraft and the conduit that this spacecraft established between its makers at the Indian Space Research Organisation (ISRO) and the Moon. I took the role of artist-mentor in what was a longterm and highly collaborative project. In this short paper I will outline some points about ownership and authorship that in retrospect were the defining criteria of that engagement. I focus on the concept of authoring by using a drawing made during Moon Vehicle to look at convergences present at an intimate distance from space technology and at what can be drawn, metaphorically, from the artifacts and processes of aesthetic and creative intervention.

I have described some episodes from the Moon Vehicle project in more detail elsewhere [1], but briefly, Moon Vehicle was the initiative of Srishti Institute of Art, Design and Technology in

E-mail address: jomagriff@gmail.com.

1 See www.aconnectiontoaremoteplace.net.
Bengaluru (Bangalore) and was one of a series of artist-led projects through which the design curriculum merged with external networks to develop new areas of design practice. Just prior to the launch of Chandrayaan in 2008, I was invited to mentor the Moon Vehicle project as artist-in-residence, having previously spent some years developing space-related projects at UC Berkeley Space Sciences Laboratory and at Mullard Space Science Laboratory, University College London. With Srishti design students I developed a series of events and workshops over two and a half years in collaboration with some of the Chandrayaan mission teams and also scientists from the Indian Institute of Astrophysics. In one event we projected the rising full Moon via a telescope attached to a camera and projector onto the rooftop of the Visvesvaraya Industrial and Technological Museum and invited an audience to share cultural and scientific interpretations of the Moon. In another activity, children living in slum areas near to ISRO interviewed mission teams and drew portraits of the ways the technologists were connected with the apparatuses they constructed and operated. There were many episodes to Moon Vehicle and from the research visits, planning meetings and workshops that happened along the way, the conversations and friendships that emerged became an extraordinary 'vehicle' for dialogue across communities. These were excellent examples of public engagement with science and space missions, but perhaps more interestingly, these creative interactions exposed the conveyance and reception of space technology across diverse and elusive social domains. As an artistic and 
creative initiative, Moon Vehicle visualized a defining problem in the enterprise of space faring: the disjuncture between the experience of alienation from the mission, felt by many, and the promise of the collective quest of space technology. Although Chandrayaan's launch brought widespread celebration, like most space missions it still offered little tangible means of participation or involvement. This problem became particularly evident as Moon Vehicle began to try to use the mission as material for new work. In this context, imaginative connections made to a technology that cannot be seen or touched become significant indicators of who authors space technology, when and where - and who does not.

\section{Authorship and ownership}

The launch of Chandrayaan-1 on 22 October 2008 from the Satish Dhawan Space Centre on the East coast of India stirred certain anxieties over the nature of the relation of the spacecraft to the population of the Indian nation. Orbiting spacecraft generate partitions between those who own space technology and those who do not. Such partitions are abstractions or imaginaries in that ownership of space technology is difficult to pin down. Do the scientists of the Indian Space Research Organisation who designed the instruments onboard Chandrayaan own it? Or do the funders, the BJP (Bharatiya Janata Party) government that in 2003 allocated funds and gave the mission the go ahead? Can the State claim ownership and if so, then does Chandrayaan belong, by dint, to the citizens of India? Or does a mission to the Moon from the Earth assume the transcendental ownership of all humanity, as often suggested by space advocates? The abstract partitions of exclusions and inclusions that form the imaginaries of space technology generate complex reactions within an affective space that is by definition hard to see and changeable. As a conceptual category, the materialist and arguably Eurocentric concerns of 'ownership' reduce tantalizing affective spaces where the imaginaries that guide space faring enterprises and the imaginaries that are structured by space faring collide. The structural ambiguity of space technology motivates an array of visible responses. Some are from artists, such as myself, whose responses include finding ways to infiltrate the enterprises of space faring, if not to seek ownership, then to lay claim to imaginaries of space technologies through the tactical poetics of authorship.

The notions of 'ownership' and 'property' are contained in the treaties governing the uses of outer space - the 1967 Outer Space Treaty and the 1979 Moon Treaty. In the Moon Treaty a section that has sparked contention is Article 11 Clause 3 that states that a nation, non-government group or "natural person" can own no part of the Moon. The treaty has not been fully ratified but its words still carry an authority that the recent spate of missions to the Moon by China, India, Japan, the United States and by ESA begin to test, as do independent initiatives to sell land on the Moon. Ownership of the Moon was a hotly debated topic at an art exhibition held in London last year called 'Republic of the Moon'. The work of artists, including the Moon Vehicle project, was presented with the wry provocation that the Moon now belongs to artists! But to adopt the existing language of ownership is to miss the more subtle ways that art and artists appropriate. The claim that artists should occupy or own the Moon follows the attention given to ownership in the language of space policy documents and in this, I suggest, there is room for a shift in thinking.

Moon Vehicle was primarily a claim for co-authorship of the Chandrayaan mission. Its significance was as a cultural vehicle for interpretation at the moment of Chandrayaan's launch. In some ways the project was a ruse by which to share in the celebration. At the same time, it responded to anxieties about the exclusivity of the mission and its disavowal of the broadly societal remit of the Indian space programme. It also responded to a much less defined and insidious consequence of space faring that could be sensed in the way space activities generated ties between techniques used for the control of non-Earth environments and the techniques used by government to control their over-complex populations. The ties between state and space agency, for instance the transfer of ISRO directors between outer space projects and governance of the nontechnological, culturally determined everyday world, begged questions, in India at least, about the structural consequences of space programmes. ${ }^{2}$ As the historian of technology Rosalind Williams argued in 1993, aesthetic intervention has become the only means of participation, appropriation or resistance towards the impositions of large-scale technological systems: "The central form of protest is no longer political but aesthetic - the capacity to apprehend differently, to create a different cognitive map" [2]. If this is so then an artist-led intervention such as Moon Vehicle visualises and exposes a structure of exclusion of which it is itself symptomatic. The question is how to decipher and learn from such interventions.

\section{Drawing space technology}

The most rewarding and critically testing episode of Moon Vehicle was a two-week workshop held at a school called Drishya Learning Centre situated close to the ISRO Satellite Centre where Chandrayaan was assembled. The learning centre is for children from communities situated in slum districts of Bengaluru. From my perspective, an important aim of Moon Vehicle was to demonstrate that the constituencies affected by space enterprises were not anonymous, complicit publics but highly capable of determining the terms of their participation in space missions, given the opportunity to do so. In this way the interaction between Drishya and ISRO was unusually charged. It was activist in many respects because it demonstrated that the space agency was not sharing the mission adequately. The ISRO scientists who participated in the workshops may have done so because they recognized the lack of effort being made at higher levels of the organisation to share the Moon mission beyond a specific and arguably privileged scientific community. Their participation actively redressed this oversight. One of the ways this happened was by mission scientists becoming part of Moon Vehicle and hosting field visits to their workplaces in ISRO.

During one such visit Shivashakti, then aged 12, made the drawings shown in Fig. 1. The left page relates to the visit made by the children on the second day of their workshop to the ISRO Satellite Centre where Chandrayaan had been assembled. During this visit the children were told about the three stages of a rocket and that at launch the satellite Chandrayaan had been in the 'nose cone' only emerging when the last stage of the rocket was in outer space, orbiting the Earth. From there its solar panels opened and it continued its journey to the Moon where it took photographs. The drawing shows this journey, including the detail that Chandrayaan turned its cameras on the Earth to photograph the eclipse of the Sun.

The huge plant or flower on the right hand page is dramatically different. Written in the petals of what may be a flower is the factual, but nonetheless poetic numerical information about the

\footnotetext{
2 Former Chairman of ISRO K. Kasturirangan has since become a member of the government Planning Commission heading a controversial report on the development of the fragile biodiversity of the Western Ghats. Former Chairman U.R. Rao has been significantly involved in education initiatives, see for example, Rao, U. R. Space Technology for Revitalising the Education System. In Subbarayappa BV, editor. Science in India Past and Present, Mumbai: Nehru Centre; 2007, p. 428-57.
} 


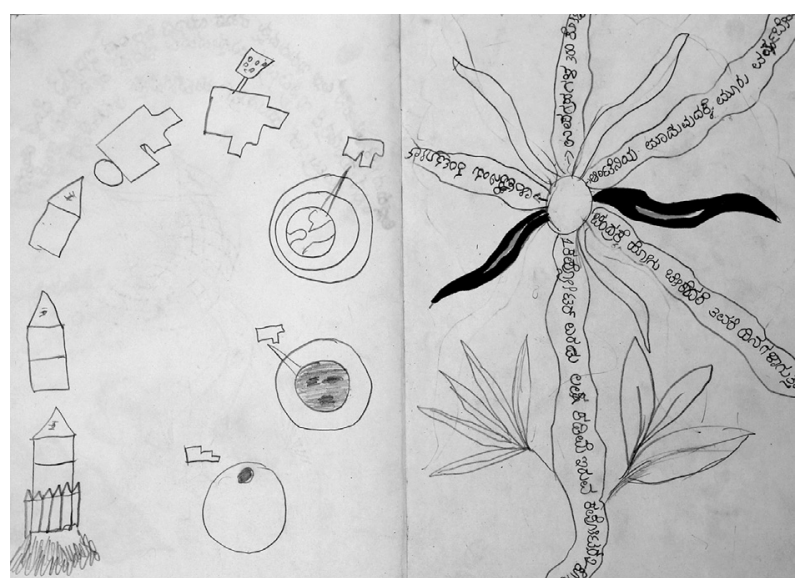

Fig. 1. Drawings of Chandrayaan made by Shivashakti, aged 12 of Drishya Learning Centre, Bengaluru (photo credit: Joanna Griffin).

mission repeatedly told to the children during their second field trip visit, which was to the Indian Deep Space Network (IDSN). Located about $30 \mathrm{~km}$ south of Bengaluru on land acquired from the nearby village of Byalalu the gently sloping, low lying basin was found to be suitable for the construction of huge deep space antenna dishes. It is here that video from Chandrayaan streamed daily from the Moon's surface onto huge video screens inside the mission control room, watched by a handful of operators and security guards. From this day's visit, Shivashakti recorded on her drawing that Chandrayaan took 3 days to reach the Moon, that it took 3 years to build and that the cost of the mission was 300 crore (a numerical unit used in India in which 1 crore $=10000$ 000). What is so arresting about the drawing is that these monotonous facts are held in the extraordinary depiction of a huge flower, or something like a flower.

A closer inspection of the drawing adds layers to its unclear origins or intentions. Some of the 'petals' are not exactly 'petal-like' but appear as artefacts from a first attempt that gradually transformed into a plant. I later discovered that the antenna dishes were described to the children during their visit as "like the petals of a flower". So the drawing could be interpreted as a 'mistake' or misunderstanding of what was meant by the scientist's analogy. Similarly, in writing that the mission cost 300 crore, there is a discrepancy in the spelling and what is actually written is the word for 'forts' or 'castles' which is very similar to the word for 'crore'. She has written "300 forts of satellites", although it might be assumed that she meant the cost of the spacecraft. The intentionality behind the writing and drawing is difficult to gauge. But intriguingly the apparent mistakes are glitches that draw attention to an ether of mediation between seeing, description and interpretation. The 300 castles of satellites and the plant-like antenna are alluring concepts, if understood as intentional, even if the meaning this had for the pupil making the drawing is elusive.

But what I find most striking and satisfying about the depiction of the huge 'flower' is its sense of drift away from the colossal constructions of space technology with which we were confronted that day. Instead the technological narrative is delightfully subsumed into something else, perhaps a narrative of the natural world, perhaps one of disinterest. The drift detectable in the drawing though is also a recontextualisation that constitutes an act of authorship. So to look again at the drawing, which by now reveals that this intimate reading of the artist and her view of space technology is a far more complex business than it seemed at first, what else can be gleaned from its provocative re-imagining?

Drawings are uncanny artefacts that remind us of what we see, what others see and the negotiation of intersubjectivities that take place within the proximal space of a person. As such, drawings indicate an affective space of interpretation and a convergence of influences on that space, such as the anecdotes the children were told on their visit, the plethora of imagery of space and Chandrayaan available in books, on the walls at ISRO, in newspapers, on television, on stickers and leaflets distributed to the children. Influences on the pupil's interpretations include my own request that they make portfolios of drawings as a record of these experiences and the influence of the pupil's drawings on each other. Yet within each portfolio of drawings is the unmistakable and distinctive, signatory authorship of each.

\section{Authoring Chandrayaan}

Why such speculation on the aesthetic decisions of Shivashakti should matter to space enterprises is that here, lightly placed, is evidence of a current of remix and drift, which opens onto the unchartered productions of the affective realm of space faring. I will dig a little deeper into this speculation because the licence to notice the infinitesimal may be both therapeutic and enlightening for the relentlessly large-scale and over-ambitious enterprises of space. Shivashakti's drawing is not without relevance to incidents of authorship implemented throughout the collective anonymity of space agencies - the unsung heroic innovations of engineers for instance, the delicate soldering of gold components onto instrument circuit boards, the architectures of project management administration. There is a symmetry here to be grasped between a collective anonymity projected onto both space agencies and publics, albeit that the cognitive agency to determine the form of space technologies is firmly aligned with the scientific space agency.

In what is a starkly different context to that of space faring, philosopher of science Sundar Sarukkai asks the question: "Is an individual the author of her own experience?" [3] in order to articulate an ethical approach to authorship. His question of authorship is motivated by a moral question as to whether anyone who is not Dalit (the Untouchable caste in India) has the right to theorize about Dalit experiences. Who owns an experience and who authors that experience demands an ethic. This question of ownership of experience opens onto the troubling lacuna in the social constituency of space technology: who speaks for the subalterns of space technology? The uncertain role of audiencepublics-oneself in relation to space missions becomes a question of ethics when the agency to author one's own experience is delimited. Am I made complicit in the 'human quest' of Chandrayaan to learn about the Moon and dubiously survey its minerals with a view to exploitation? If not, then by what means do I indicate that I have opted out? The problem of sublation is of course not limited to technocracy and it is not a simple matter of division between space technologists and publics. What was interesting about the experience of Moon Vehicle was that similar wishes to contend authorship appeared to be shared by mission scientists. My own intentions to bring artistic authorship into the frame of the astronautical communities is motivated by a wish to assert, pursue and articulate authorship within collectivity - to modulate the imaginaries of spaceflight rather than sublate into the authorship of organisational space technology production or state iconography.

\section{In conclusion}

The conceptual category of authorship exposes affective spaces of space faring that are often reductively articulated through legal, policy and technical discourse. Artist's critical and creative 
engagements offer an enrichment of terms above and beyond the materialist claim for ownership through a capability to be attentive to private reflection and intention. Aesthetic interventions signal apposite conceptual categories that shift attention to the ways space technology is thought about. Because of this the notion of authorship associated with creativity expands the criteria from which space policy and space activities emerge and to which they are subject.

\section{Acknowledgements}

Thanks to participants of Moon Vehicle at Srishti Institute of Art, Design and Technology, Drishya Learning Centre, the Indian Space Research Organisation and the Indian Institute of Astronomy. Thanks also to The Arts Catalyst, the producers of the exhibition Republic of the Moon and the Global Lunar Day symposium from which the opportunity to write this paper emerged. The initial research for this paper was carried out as part of doctoral research at Plymouth University funded by the Arts and Humanities Research Council (2009/145983) with supervisors Prof. dr. Michael
Punt and Dr. Martha Blassnigg at Transtechnology Research. My thanks to Madhava Chipalli for his careful translation of the Kannada script in Shivashakti's drawing from Kannada to English and special thanks to Shivashakti.

\section{References}

[1] Joanna Griffin, Moon Vehicle: Reflections from an artist's-led children's workshop on the Chandrayaan-1 spacecraft's mission to the Moon, Leonardo 45 (3) (2012) 219-224

[2] Rosalind Williams, Cultural origins and environmental implications of large technological systems, Sci. Context 6 (2) (1993) 377-403, 399.

[3] G. Guru, S. Sarukkai, The cracked mirror: an Indian debate on experience and theory, Oxford University Press, New Delhi, 2012, p. 38.

The author completed her Doctorate 'Experience and Viewpoints in the Social Domain of Space Technology' with the Transtechnology Research group at Plymouth University. As well as Moon Vehicle she created Satellite Stories at the Mullard Space Science Lab, University College London (commissioned by The Arts Catalyst and funded by UCL Beacons for Public Engagement) and in 2006-7 received an International Arts Council of England Artists Fellowship at the NASA funded Space Sciences Lab, UC Berkeley. 